\title{
Assessment of air quality after the implementation of compressed natural gas as fuel in public transport in Delhi, India.
}

\author{
Khaiwal Ravindra ${ }^{*}$, Eric Wauters ${ }^{2}$, Sushil K. Tyagi ${ }^{3}$, Suman Mor ${ }^{4}$ and René \\ Van Grieken ${ }^{1}$ \\ ${ }^{1}$ Micro and Trace Analysis Center, Department of Chemistry, University of \\ Antwerp, Universiteitsplein 1, B-2610 Antwerp, Belgium \\ 2 Flemish Environment Agency (VMM), Krijgslaan 281, S2, B-9000 Gent, Belgium \\ ${ }^{3}$ Central Pollution Control Board, Parivesh Bhawan, Delhi - 110032, India \\ ${ }^{4}$ Centre for Energy Studies, Indian Institute of Technology Delhi, Hauz Khas, New \\ Delhi-110016, India
}

\begin{abstract}
Public transport in Delhi was amended by the Supreme Court of India to use Compressed Natural Gas (CNG) instead of diesel or petrol. After the implementation of CNG since April 2001, Delhi has the highest fraction of CNG-run public vehicles in the world and most of them were introduced within 20 months. In the present study, the concentrations of various criteria air pollutants $\left(\mathrm{SPM}, \mathrm{PM}_{10}, \mathrm{CO}, \mathrm{SO}_{2}\right.$ and $\mathrm{NO}_{\mathrm{x}}$ ) and organic pollutants such as benzene, toluene, xylene (BTX) and polycyclic aromatic hydrocarbons (PAHs) were assessed before and after the implementation of CNG. A decreasing trend was found for PAHs, $\mathrm{SO}_{2}$ and $\mathrm{CO}$ concentrations, while the $\mathrm{NO}_{\mathrm{x}}$ level was increased in comparison to those before the implementation of CNG. Further, SPM, $\mathrm{PM}_{10}$, and BTX concentrations showed no significant change after the implementation of CNG. However, the BTX concentration demonstrated a clear relation with the benzene content of gasoline. In addition to the impact of the introduction of $\mathrm{CNG}$ the daily variation in PAHs levels was also studied and the PAHs concentrations were observed to be relatively high between $10 \mathrm{pm}$ to 6 am, which gives a proof of a relation with the limited day entry and movement of heavy vehicles in Delhi.
\end{abstract}

Key words: $\mathrm{CNG}$, public transport, $\mathrm{CO}, \mathrm{NO} \mathrm{O}_{x}, \mathrm{SO}_{2} \mathrm{PM}_{10}, \mathrm{BTX}, \mathrm{PAHs}$, principal component analysis.

*Corresponding Author: Ravindra Khaiwal, Micro and Trace Analysis Center, University of Antwerp, Antwerp B-2610, Belgium, e-mail: khaiwal.ravindra@ua.ac.be or khaiwal@yahoo.com 


\section{Introduction}

The Indian economy grew by 2.63 times between 1975 and 1995, while the industrial pollution load grew by 3.47 times and the vehicular pollution load by 7.5 times (Kumar and Bhattacharya, 1999), which indicates that almost all Indian cities, particularly metropolitan cities such as Delhi, Mumbai and Kolkata, are reeling under severe air pollution. There were 2.5 million vehicles registered in Delhi during 1996, while this number has reached 4.17 million in 2004 (Transport Department, 2004). Vehicular pollution accounts significantly to the total pollution generated in Delhi (Economic Survey of Delhi, 2003-04; Gurjar et al., 2004). The most common method of public transport in Delhi comprises buses, minibuses, taxies and three wheelers. Their consumption of diesel is higher as compared to gasoline than possibly anywhere in the Western World. Further, diesel constitutes two-third of the total fuel consumption in the transport sector (Aggarwal, 1999).

Diesel exhaust is considered to contain various substances, which are hazardous to human health (Aggarwal, 1999). Further, it produces 10 to 100 times more particles than gasoline. The Scientific Review Panel of the California Air Resources Board points out that a chronic exposure to $1 \mu \mathrm{g} \mathrm{m}^{-3}$ of diesel exhaust will lead to 300 additional cases of lung cancer per million people (S.R.P., 1998). For a population of fourteen million in Delhi, this means 4200 extra cases of lung cancer for a chronic exposure to $1 \mu \mathrm{g} \mathrm{m}^{-3}$ of diesel exhaust. Diesel exhaust has a higher potency to causing cancer than benzene, a potent carcinogen compound produced in gasoline exhaust, which is implicated in leukemia. Further, the suspended particulate matter (SPM) concentration in India exceeds the annual mean guideline of the World Health Organization (WHO) for 294 days in Delhi and 268 days in Kolkata (Brandon and Homman, 1995). About 40000 Indians are dying early every year because of air pollution: 7500 in Delhi, 5700 in Mumbai and 4500 in Kolkata, and it has been estimated that these deaths can be avoided in Delhi by a 142 $\mu \mathrm{g} \mathrm{m}^{-3}$ reduction in $\mathrm{PM}_{10}$. The study also estimates that India spends US\$ 350 to 490 million every year on the treatment of diseases that are caused by ambient air pollution (Brandon and Homman, 1995). One out of every ten school children in Delhi suffers from asthma that is worsening due to air pollution (Aggarwal, 1999). 
A report prepared by Centre for Science and Environment (C.S.E., 2001) shows that in cities, facing severe air pollution problems, the use of heavy-duty natural gas engines, in place of diesel, offers numerous environmental benefits. Further a report by the Australian Government Council for Scientific and Industrial Research Organization (CSIRO) also supports the same (Beer et al., 2000). This has led Tehran, Los Angeles, Bangkok, Santiago, Cairo, Beijing and many other cities to establish a natural gas programme (Dursbeck et al., 2001). In view of the seriousness of the health effects of air pollution and to improve the air quality of Delhi, the Supreme Court of India passed an order on July 28, 1998 to reduce vehicular pollution. In brief, the Supreme Courts Directives were as follows:

- Augmentation of public transport (stage carriage) to 10,000 buses till $1^{\text {st }}$ April 2001.

- Replacement of all pre-1990 autos and taxies with new vehicles on clean fuels till March 1, 2000.

- Financial incentives for replacement of all post 1990 autos and taxies with new vehicles on clean fuel by March 31, 2000.

- Buses older than 8 years are not allowed to ply without Compressed Natural Gas (CNG) or other clean fuels by April 1, 2000.

- Entire city bus fleet to be steadily converted to single fuel mode by March 31, 2001.

- Gas Authority of India Limited (GAIL) to expedite and expand from 9 to 80 CNG supply outlets by March 31, 2000 in Delhi.

After the implementation of CNG since April 2001, Goyal and Sidhartha (2003) reported the trends of $\mathrm{CO}, \mathrm{SO}_{2}, \mathrm{NO}_{\mathrm{x}}$ and $\mathrm{SPM}$ concentration till the end of 2001, although during this period only a small fraction of public transport was converted to CNG. In the present study we have appraised the air quality when most of the vehicles were converted to CNG and Delhi achieved the highest number of CNG-run vehicles in the world (Transport Department, 2004; Table 1). Furthermore, we have also assessed the variations in concentration of BTX, PAHs and respirable particles $\left(\mathrm{PM}_{10}\right)$ in view of their 
complex association with health effects (Ravindra et al., 2001). Further the spatial and temporal variations in PAHs concentrations were also assessed and an attempt has been made to find the potential sources of PAHs in Delhi.

\section{Materials and Methods}

The ambient air quality data for $\mathrm{CO}, \mathrm{SO}_{2}, \mathrm{NO}_{\mathrm{x}}, \mathrm{SPM}, \mathrm{BTX}$ and PAHs between 1997 to 2003 was acquired from the Central Pollution Control Board (CPCB, Delhi), monitored near a traffic intersection near Bahadur Shah Zafar (BSZ) road in downtown Delhi (NAAQMS, 1998-2004). The monitoring of pollutants has been carried out for $24 \mathrm{~h}$ (4 hourly sampling for $\mathrm{SO}_{2}, \mathrm{NO}_{\mathrm{x}}$ and 8 hourly for SPM) at a height of 3-5 m with a frequency of twice a week, thus giving 104 observation days in a year.

As there were no data available for PAHs after the year 2000, a representative number of samples were collected from BSZ, and Sirifort residential site (SF) using APM-460, 415 (Envirotech, Delhi) high volume sampler from January to March 2003. Samples for the measurement of PAHs concentrations from $\mathrm{PM}_{10}$ were collected by APM-460 RDS (Envirotech, Delhi) respirable dust sampler. Air was drawn through a 20 x $25 \mathrm{~cm}$ glass fiber filter (GFF) sheet at a flow rate of 0.8 to $1.2 \mathrm{~m}^{3} \mathrm{~min}^{-1}$. After this, the filter samples were separately wrapped in aluminum foil and stored in a freezer at $-20{ }^{\circ} \mathrm{C}$, until they were processed.

For PAHs determinations, the filter samples were extracted using pressurized liquid extraction (Dionex, Titan Way, California, USA) for the fast extraction of PAHs with minimum solvent consumption (Godoi et al., 2004; Ravindra et al., 2005). The extracts were concentrated in a Turbo Vap 500 (Zymark, Hopkinton, MA, USA) concentrator. The solvent was replaced to $1 \mathrm{ml}$ acetonitrile prior to their analysis for the separation and detection of 10 PAHs compounds by HPLC in combination with programmed fluorescence detection. The detected and quantified PAHs were: fluoranthene (FluT), pyrene (Pyre), benzo(a)anthracene (BaA), chrysene (Chry), benzo(b)fluoranthene (BbF), benzo(k)fluoranthene $(\mathrm{BkF})$, benzo(a)pyrene $(\mathrm{BaP})$, dibenzo(a,h)anthracene (DahA), benzo(g,h,i)perylene (BghiP) and indeno(1,2,3-c,d)pyrene (IND). The HPLC system consisted of a liquid chromatography system (Waters, Milford, MA, USA) and a fluorescence detector (Perkin-Elmer LC240, Main Ave, Norwalk, CT, USA). Separation 
of the PAHs was accomplished using a Vydac 201TP column (250 mm x $4.6 \mathrm{~mm}$ ), with a gradient elution ranging from a 50/50 acetonitrile-water mixture to $100 \%$ acetonitrile in $20 \mathrm{~min}$. The fluorescence of PAHs was monitored with automatic adjustment of the wavelength for each compound according to their retention time on the HPLC column. The excitation wavelengths ranged between 260 and $300 \mathrm{~nm}$, the emission wavelengths between 380 and $465 \mathrm{~nm}$. The standard reference material SRM1647 (NIST) was used for calibration of the quantification method.

The sampling of BTX was performed by using Radiello diffusive tubes (Fondazione Salvatore Maugeri (FSM), Padova, Italy), filled with activated charcoal cartridges (F.S.M., 2000). Two parallel Radiello diffusion tubes were exposed to air for a week, two times a month at each site from January to June 2003. The samples were extracted from the cartridges in carbon disulphide and analyzed on Capillary GC equipped with flame ionization detector (CP 3800, Varian, Walnut Creek, CA, USA). A $50 \mathrm{~m}$ X 0.21mm i.d. WCOT fused silica (Chromopack, Middelburg, The Netherlands) capillary column with a film thickness of $0.5 \mu \mathrm{m}$ was used. The temperature program started at $60{ }^{\circ} \mathrm{C}$ and increased up to $230{ }^{\circ} \mathrm{C}$ with a $10{ }^{\circ} \mathrm{C} \mathrm{min}^{-1}$ heating rate.

\section{Results and Discussions}

\section{Impact of introduction of CNG on PAHs}

The average concentration of PAHs samples collected during early 2003 at the BSZ and SF sites were compared with the mean PAHs level at the same sites prior to the CNG implementation (Fig. 1). Total annual average PAHs concentrations of $38.2 \mathrm{ng} \mathrm{m}^{-3}$ (1997), $24.6 \mathrm{ng} \mathrm{m}^{-3}$ (1998), $14.5 \mathrm{ng} \mathrm{m}^{-3}$ (1999), and $22.3 \mathrm{ng} \mathrm{m}^{-3}$ (2000) were reported at these sites (C.P.C.B., 2003). The concentrations of PAHs are generally observed to be higher during winter than in the other seasons (Cotham and Bidleman, 1995; Harrison et al., 1996). Hence the compared values of PAHs used in Fig. 1 for 2003 may fall further, if the annual average value will be used. Further, a comparison of the monthly average (winter) values of the total PAHs at BSF is given in Fig. 2. There were no data available for the year 2001 and 2002. For 2003, the total average PAHs concentrations were 11.5 $\mathrm{ng} \mathrm{m}^{-3}$ and $4.52 \mathrm{ng} \mathrm{m}^{-3}$, for the BSZ and SF sites, respectively. The variations within individual PAHs levels are also depicted in Fig. 1. The comparison of these PAH 
concentrations with those prior to $\mathrm{CNG}$ implementation demonstrates a significant decrease. This fall in PAHs concentrations may be related to the total aromatic and PAHs contents in diesel, as there is no maximum limit proposed in India, whereas in Europe, diesel may contain a maximum of up to $10 \mathrm{ppm}$ of total aromatics and $1 \mathrm{ppm}$ of PAHs. Further, there is a sharp fall in the use of diesel and petrol by the public transport vehicles after the implementation of $\mathrm{CNG}$, which also indicates the likely reason for this decrease in PAHs levels in Delhi. Although there is a continuous increase in the demand of diesel and petrol (Table 2), it can be expected that a part of the total energy demand by the transport sector is being fulfilled by an additional source, i.e. $\mathrm{CNG}$, which is expected to increase in subsequent years due to $\mathrm{CNG}$ changeover.

\section{Spatial and temporal variation in PAHs concentrations}

The daily variations within individual PAHs concentrations and temporal pattern in SPM and $\mathrm{PM}_{10}$ are shown in Fig. 3 and 4 for BSZ and SF, respectively. The concentrations of PAHs were found to be slightly less (10-20\%) in the $\mathrm{PM}_{10}$ fraction in comparison to SPM. This can also be evident as the $\mathrm{PM}_{10}$ forms a major fraction of SPM in Delhi. The maximum concentration of PAHs at BSZ was noticed between $10 \mathrm{pm}$ to 6 am, which most likely indicates the entry of heavy vehicles (trucks, trolley, vans etc.) through this important traffic intersection in Delhi. This type of traffic increases in the late evening hours (after $10 \mathrm{pm}$ ) due to restricted entry of heavy vehicles into the metropolitan city of Delhi at daytime. These vehicles still run on diesel rather a CNG, because the CNG has been only implemented in Delhi, whereas these vehicle belongs to other states, which still have relaxed norms for vehicle exhaust in comparison to Delhi. A similar pattern of criteria pollutants has been reported by Ravindra et al., 2003, in Delhi near the entry point of these vehicles, which also indicates the same source of origin, i.e. vehicular emission. Another possible reason seems to be related with vapor pressure of PAHs: due to their low vapor pressure they may be present in vapor phase during the day while at night, with the fall of temperature they may condense and/ or adsorb on particles. At the residential site, the highest concentration of PAHs was noticed between 6 am to 2 pm, when a maximum activity of personal and public vehicles can be seen in these areas. Moreover the total PAHs concentration at residential sites $\left(4.5 \pm 2.0 \mathrm{ng} \mathrm{m}^{-3}\right)$ was found to 
be 2 to 3 times lower than at the traffic intersection $\left(11.5 \pm 3.3 \mathrm{ng} \mathrm{m}^{-3}\right)$, and likely points towards a smaller traffic density.

\section{Potential sources of PAHs in Delhi}

\section{Evaluation of diagnostic ratio}

Except the public transport vehicles that run on CNG, Delhi has also a large number of personal cars and two-wheelers (motorbikes and scooters) and hence the diagnostic ratio of IND/ (IND+BghiP), FluT/ (FluT+Pyre) and $\mathrm{BaP} /(\mathrm{BaP}+\mathrm{Chry}$ ) were used to identify the possible emission sources of PAHs (Table 3). A higher diagnostic ratio (> 0.5) of IND/ (IND+BghiP) and FluT/ (FluT+Pyre) has been used as an indication towards diesel emission sources (Kavouras et al., 2001). The ratio of BaP / (BaP+Chry) was 0.49 for gasoline emissions and 0.73 for diesel engines (Khalili et al., 1995; Guo et al., 2003). In comparison to these studies, the present results suggest that diesel and gasoline emission sources existed simultaneously at BSZ and SF sites. Diesel driven goods vehicles ply during nighttime primarily, and dominated more at BSZ as compared to SF, where gasoline emission may be the major source of PAHs probably due the frequent use of two-wheelers in the vicinity of the sampling site.

\section{Principal component analysis}

In order to enhance the accuracy of emission source identification at the BSZ and SF sampling sites, principal component analysis (PCA) was used. Source grouping was determined using PCA with varimax rotation and the retention of principal components having an eigenvalue $>1$ of complete data set of PAHs concentration. Factor analysis in this study was carried out using the statistical analysis SPSS 12.0 software package. Table 3 provides the results of factor analysis of total PAHs concentrations at BSZ and SF sampling sites. The PCA results show that two factors explain the main part of data variance.

The high factor loading of FluT, Pyre, BaP and BghiP in Table 4 for factor 1 confirmed that vehicular emission was one of the major sources of PAHs at both BSZ and SF sites. This is a similar observation to that of Guo et al. (2003). Some authors report that the higher concentrations of FluT, Pyre and, especially, BghiP and coronene indicate 
towards gasoline-fueled vehicles, while the higher concentrations of FluT, Pyre with higher ratio of $\mathrm{BbF}$ and $\mathrm{BkF}$ point to the emission of $\mathrm{PAHs}$ from diesel powered vehicles (Duval et al., 1981; Masclet et al., 1986; Khalili et al., 1995). On the basis of these studies it can be concluded that diesel vehicles form a major fraction of PAHs concentration at BSZ and SF sampling site. The high factor loading of FluT and Pyre for factor 2 at BSZ also indicates towards oil burning (Duval et al., 1981). The high loading of FluT and Pyre with BghiP and IND for factor 2 indicated that gasoline engine emission also affects the air quality at the SF sampling site (Fang et al., 2004).

\section{Impact of introduction of CNG on BTX}

The samples collected during winter and summer at BSZ and SF were analyzed for BTX concentrations. There is no significant change in the BTX concentration noticed after the implementation of CNG (Fig. 5). Still the total BTX concentration shows a clear relation to the benzene content of fuel and a sharp reduction in total average BTX concentration from $95 \mu \mathrm{g} \mathrm{m}^{-3}$ to $18 \mu \mathrm{g} \mathrm{m}^{-3}$ was noticed after the reduction of the benzene content from $3 \%$ to $1 \%$ in petrol in the national capital territory after November 2000 (C.P.C.B., 2002). Further, no significant difference in total average BTX concentration was observed in winter $\left(22 \pm 10 \mu \mathrm{g} \mathrm{m}^{-3}\right)$ in comparison to summer $\left(20 \pm 8 \mu \mathrm{g} \mathrm{m}^{-3}\right)$ during 2003.

\section{Impact of introduction of CNG on criteria pollutants}

The variation in annual average concentrations of various criteria pollutants (SPM, $\mathrm{PM}_{10}, \mathrm{CO}, \mathrm{SO}_{2}$ and $\mathrm{NO}_{\mathrm{x}}$ ) at $\mathrm{BSZ}$, over the period of 1998 to 2003 are shown in Fig. 6. After the implementation of $\mathrm{CNG}$, the $\mathrm{CO}$ and $\mathrm{SO}_{2}$ concentrations develop a decreasing trend, whereas the $\mathrm{NO}_{\mathrm{x}}$ concentration seems to be increasing. The explanation for increasing $\mathrm{NO}_{\mathrm{x}}$ concentration seems to be related with the significant increase in total number of vehicles each year in Delhi and with the higher flash-point of $\mathrm{CNG}\left(540{ }^{\circ} \mathrm{C}\right)$ compared to that of diesel $\left(232-282^{\circ} \mathrm{C}\right)$. At such a high temperature, more nitrogen from the air compresses and reacts with oxygen in the combustion chamber of CNG driven vehicles and thus produces more $\mathrm{NO}_{\mathrm{x}}$. Further, the concentration ratios of $\mathrm{CO} / \mathrm{NO}_{\mathrm{x}}$ and $\mathrm{SO}_{2} / \mathrm{NO}_{\mathrm{x}}$ were also compared to characterize the emission sources. For the period of 
1998 to 2000 , the $\mathrm{CO} / \mathrm{NO}_{\mathrm{x}}$ and $\mathrm{SO}_{2} / \mathrm{NO}_{\mathrm{x}}$ ratios were 81 and 0.36 respectively, while after the implementation of $\mathrm{CNG}$ the respective ratios were 46 and 0.15 for $\mathrm{CO} / \mathrm{NO}_{\mathrm{x}}$ and $\mathrm{SO}_{2} / \mathrm{NO}_{\mathrm{x}}$. The high $\mathrm{CO} / \mathrm{NO}_{\mathrm{x}}$ ratio and low $\mathrm{SO}_{2} / \mathrm{NO}_{\mathrm{x}}$ ratio at $\mathrm{BSZ}$ indicates toward vehicular emission sources.

A study conducted by CPCB (1995) shows that $97 \%$ of hydrocarbon (HC), $76 \%$ of $\mathrm{CO}$ and $50 \%$ of $\mathrm{NO}_{\mathrm{x}}$ emission comes in air from vehicular activity and hence a fall/increase in the levels of these pollutants can be related to the CNG implementation. Further the report shows that vehicular emission contributes around $10 \%$ of the total emission of $\mathrm{SPM}$ and $\mathrm{SO}_{2}$ in Delhi. A significant fall in $\mathrm{SO}_{2}$ concentrations was noticed prior to CNG implementation and that can be attributed to the use of refined (low S) coal in power stations, the reduction of the $\mathrm{S}$ content in diesel and the shifting/relocation of industries from residential to industrial sites. Further a slight fall in $\mathrm{SO}_{2}$ concentration noticed even after 2001 may be related to the CNG implementation.

A decrease in annual average concentration of particles (SPM and $\mathrm{PM}_{10}$ ) was noticed in 2001 (Fig. 6) and Goyal and Sidhartha (2003) related it with the CNG implementation, but it shows an increase in subsequent years. And hence the concentration of particles seems not only related with vehicular pollution, but also with small scale industries, domestic coal burning, thermal power plants and natural sources like 'Andhi', the dust storm from the Thar desert of neighboring Rajasthan state during the pre monsoon period. Delhi, with its semi arid climate, experiences three seasons: (i) the dry summer season from April through June, (ii) the monsoon season from July through September and (iii) winter season from October through March. The problem of SPM is more acute during the summer seasons due to local dusty conditions, although it falls significantly during monsoon by rain scavenging (Ravindra et al., 2003). During the winter seasons, the lower ambient temperature, lower mixing depth, temperature inversion condition and higher consumption of fuel aggravate the pollution problems (Ravindra et al., 2003b).

CNG powered vehicles emit $85 \%$ less $\mathrm{NO}_{\mathrm{x}}, 70 \%$ less reactive $\mathrm{HCs}$ and $74 \%$ less $\mathrm{CO}$ than similar gasoline powered vehicles (http://daq.state.nc.us/motor/cng/). However the comparison of the annual average concentration of $\mathrm{CO}, \mathrm{SO}_{2}$ and $\mathrm{PAHs}$, before and after the implementation of $\mathrm{CNG}$, shows approximately $50 \%$ reduction of these pollutants in ambient air of Delhi, except for $\mathrm{NO}_{\mathrm{x}}$, which shows a 10 to $20 \%$ increase in 
the subsequent years. To some extent, the gradual increase in total number of vehicles in Delhi may also contribute to increasing trend for NOx, SPM and $\mathrm{PM}_{10}$. Further the catalytic convertors are not used efficiently specially in buses, trucks and luggage carriers in India, and are hardly changed even after poor performance.

\section{Conclusion}

The concentration of $\mathrm{CO}, \mathrm{SO}_{2}$ and $\mathrm{PAHs}$ developed a significant decrease after the implementation of $\mathrm{CNG}$ and support $\mathrm{CNG}$ as an alternative to diesel or petrol fuelled vehicles, but an increase in $\mathrm{NO}_{\mathrm{x}}$ concentration was noticed. The concentrations of BTX, SPM and $\mathrm{PM}_{10}$ show no significant changes. Still, a fall in BTX concentration was noticed after the reduction of the benzene content in petrol. Further, the SPM and $\mathrm{PM}_{10}$ concentrations in Delhi seem to be related not only with vehicular emissions, but also with other anthropogenic and natural emission sources. The spatial pattern of PAHs concentration shows comparatively high concentration during late night and early morning hours, and it proves to be related with the late night movement of heavy vehicles from nearby states through Delhi. Further, the application of diagnostic ratios and PCA also characterize vehicular emission as a major PAHs emissions source. 


\section{References}

Aggarwal, A.: 1999, Engines of the devil: why dieselisation of private automobile fleet should be banned-The case study of Delhi, Centre for Science and Environment, New Delhi. (http://www.cseindia.org/campaign/apc/pdf/dieselmo.pdf).

Beer, T., Grant, T., Brown, R., Edwards, J., Nelson, P., Watson, H. and Williams D.: 2000, 'Life-cycle emissions analysis of alternative fuels for heavy vehicles', Report C/0411/1.1/F2, CSIRO Division of Atmospheric Research, Aspendale, Vic., xxi, pp 125.

Brandon, C. and Homman, K.: 1995, 'The cost of inaction: valuing the economic-wide cast of environmental degradation in India', Asia Environment Division, World Bank, 17 October 1995.

C.P.C.B.: 1995 'Annual Reports 1993/94', Central Pollution Control Board, Ministry of Environment and Forest, Delhi-32 (www.cpcb.nic.in).

C.P.C.B.: 2002 'Parivesh: Benzene in air and its effects on human health', February 2002, Central Pollution Control Board, Ministry of Environment and Forest, Delhi-32 (www.cpcb.nic.in).

C.P.C.B.: 2003 'Parivesh: Polycyclic Aromatic Hydrocarbons (PAHs) in air and their effects on human health', November 2003, Central Pollution Control Board, Ministry of Environment and Forest, Delhi-32 (http://www.cpcb.delhi.nic.in/ph/ch81103.htm).

C.S.E.: 2001 'The Smokescreen of Lies: Myths and Facts about CNG, Right to Clean Air Campaign Team', Centre for Science and Environment, New Delhi. (http://www.cseindia.org/campaign/apc/myths_facts/index_final.htm).

Cotham, W.E., and Bidleman, T.F.: 1995, 'Polycyclic aromatic hydrocarbons and polychlorinated-biphenyls in air at an urban and rural site near Lake Michigan', Environmental Science and Technology 29, 2782-2789. 
Dursbeck, F., Erlandsson, L., and Weaver C.: 2001, Status of Implementation of CNG as a Fuel for Urban Buses in Delhi: Findings-Conclusions - Recommendations, Report done for Centre for Science and Environment, New Delhi, May 23.

( http://www.cseindia.org/campaign/apc/pdf/CNGEXPER.PDF).

Duval, M.M., and Friedlander, S.K.: 1981, 'Source resolution of polycyclic aromatic hydrocarbons in Los Angeles atmosphere - application of CMB with first order decay' US EPA Report No EPA-600/2-81-161.

Economic Survey of Delhi: 2003-04, Government of National Capital Territory of Delhi, 6th Level, B-Wing, Delhi Secretariat, I. P. Estate, New Delhi, India. http://delhiplanning.nic.in/

Fang, G.C., Wu, Y.S., Chen, M.H., Ho, T.T., Huang, S.H., and Rau, J.Y.: 2004, 'Polycyclic aromatic hydrocarbons study in Taichung, Taiwan, during 2002-2003' Atmospheric Environment 38, 3385-3391.

Fondazione Salvatore Maugeri (F.S.M.).: 2000, Instruction for volatile organic (VOCs) sampling by Radiello and carbon disulfide recovery, Environmental Research Centre, 16I35127, Padova, SOVchim-UK-398.

Godoi, A.F.L., Ravindra, K., Godoi, R.H.M., Andrade, S.J., Santiago-Silva, M., Van Vaeck, L., and Van Grieken, R.: 2004, 'Fast Chromatographic determination of polycyclic aromatic hydrocarbon in aerosol samples from sugar cane burning', Journal of Chromatography A, 1027, 49-53.

Goyal, P., and Sidhartha.: 2003, 'Present scenario of air quality in Delhi: a case study of CNG implementation', Atmospheric Environment 37, 5423-5431. 
Guo, H., Lee, S.C., Ho, K.F., Wang, X.M. and Zou, S.C.: 2003, 'Particle-associated polycyclic aromatic hydrocarbons in urban air of Hong Kong', Atmospheric Environment 37, 5307-5317.

Gurjar, B.R., J.A. van Aardenne, J. Lelieveld, and Mohan, M.: 2004, 'Emission estimates and trends (1990-2000) for megacity Delhi and implications', Atmospheric Environment $38,5663-5681$.

Harrison, R.M., Smith, D.J.T., and Luhana, L.: 1996, 'Source apportionment of atmospheric polycyclic aromatic hydrocarbons collected from an urban location in Birmingham, UK', Environmental Science and Technology 30, 825-832.

Kavouras, I.G., Koutrakis, P., Tsapakis, M., Lagoudaki, E., Stephanou, E.G., Baer, D.V. and Oyola, P.: 2001, 'Source apportionment of urban particulate aliphatic and polynuclear aromatic hydrocarbons (PAHs) using multivariate methods', Environmental Science and Technology 35, 2288-2294.

Khalili, N.R., Scheff, P.A. and Holsen, T.M.: 1995, 'PAH source fingerprints for coke ovens, diesel and gasoline engines, highway tunnels, and wood combustion emissions', Atmospheric Environment 29, 533-542.

Kumar, P., and Bhattacharya, S.: 1999, 'When wealth is not health', Down to Earth 7, 33.

Masclet P., Mouvier, G., and Nikolaou, K.: 1986, 'Relative decay index and sources of PAH', Atmospheric Environment 20, 439-436.

NAAQMS series.: 1998-2004, Ambient air quality monitoring status of Delhi, Central Pollution Control Board, Delhi-32. 
Ravindra, K., Bencs, L., Wauters, E., de Hoog, J., Deutsch, F., Roekens, E. , Bleux, N., Bergmans P., and Van Grieken, R.: 2005, 'Seasonal and site specific variation in vapor and aerosol phase PAHs over Flanders (Belgium) and their relation with anthropogenic activities', Atmospheric Environment, Communicated.

Ravindra, K., Mittal, A.K. and Van Grieken, R.: 2001, 'Health risk assessment of urban suspended particulate matter with special reference to polycyclic aromatic hydrocarbons: A review', Review on Environmental Health, 16, 169.

Ravindra, K., Mor, S., Ameena, Kamyotra, J.S., and Kaushik C.P.: 2003a, 'Variation in spatial pattern of various air pollutants before and during initial rain of monsoon', Environmental Monitoring and Assessment 87, 145-153.

Ravindra, K., Mor, S., and Kaushik C.P.: 2003b. Short-term variation in air quality associated with firework event: A case study. Journal of Environmental Monitoring, 5, 260-264.

Scientific Review Panel (S.R.P.).: 1998, 'Findings of the Scientific Review Panel on The Report on Diesel Exhaust as adopted at the Panel's April 22, 1998' (www.arb.ca.gov/toxics/dieseltec/de-fnds.htm).

Transport Department.: 2004, Government of NCT of Delhi, New Delhi, (http://transport.delhigovt.nic.in/). 
Table 1: Total number of CNG vehicles in Delhi after March 2001.

\begin{tabular}{|l|c|c|c|c|c|c|}
\hline \multirow{2}{*}{ Date } & \multicolumn{6}{|c|}{ Vehicle Category } \\
\cline { 2 - 7 } & Buses & Mini Buses & Taxies & Three wheeler & Private cars & Total \\
\hline $31 / 03 / 2001$ & 400 & 250 & 2200 & 14000 & 9500 & 26350 \\
\hline $31 / 03 / 2002$ & 4231 & 2165 & 4816 & 35678 & 10350 & 57240 \\
\hline $31 / 03 / 2003$ & 8874 & 4935 & 5155 & 49810 & 10350 & 79123 \\
\hline $31 / 10 / 2003$ & 9855 & 5146 & 5337 & 55101 & 10481 & 85920 \\
\hline
\end{tabular}

Table 2: Growth in diesel consumption versus petrol consumption in Delhi

\begin{tabular}{|l|c|c|c|}
\hline $\begin{array}{l}\text { Growth in } \\
\text { consumption of }\end{array}$ & $1988-81$ to 1990-91 & 1990-91 to 1996-97 & 1996 to 2001 \\
\hline Petrol & $159 \%$ & $31 \%$ & $33 \%$ \\
\hline Diesel & $83 \%$ & $69 \%$ & $38 \%$ \\
\hline
\end{tabular}

Table 3: Diagnostic ratio between total PAHs for BSZ and SF sampling sites.

\begin{tabular}{|l|c|c|c|}
\hline \multirow{2}{*}{ Sites } & \multicolumn{3}{|c|}{ Diagnostic Ratio } \\
\cline { 2 - 4 } & IND/ (IND+BghiP) & FluT/ (FluT+Pyre) & BaP/ (BaP+Chry) \\
\hline BSZ & 0.58 & 0.62 & 0.53 \\
\hline SF & 0.62 & 0.63 & 0.46 \\
\hline
\end{tabular}


Table 4: Factor analysis of total PAHs concentration data set for BSF and SF sampling sites.

\begin{tabular}{|l|c|c|c|c|}
\hline \multirow{2}{*}{ PAHs compounds } & \multicolumn{2}{|c|}{ BSZ sampling site } & \multicolumn{2}{c|}{ SF sampling site } \\
\cline { 2 - 5 } & Factor 1 & Factor 2 & Factor 1 & Factor 2 \\
\hline Flut & 0.72 & -0.63 & 0.72 & 0.69 \\
Pyre & 0.76 & -0.55 & 0.39 & 0.81 \\
BaA & 0.55 & 0.62 & 0.92 & -0.09 \\
Chry & 0.91 & -0.11 & 0.86 & 0.46 \\
BbF & 0.99 & -0.00 & 0.99 & 0.03 \\
BkF & 0.98 & 0.05 & 0.99 & -0.01 \\
BaP & 0.96 & 0.13 & 0.96 & -0.21 \\
DahA & 0.81 & 0.30 & 0.53 & -0.37 \\
BghiP & 0.93 & -0.61 & 0.81 & -0.53 \\
IND & 0.82 & 0.33 & 0.44 & -0.72 \\
& & & & \\
\hline Eigen value & 7.28 & 1.32 & 6.27 & 2.30 \\
Varience (\%) & 73 & 13 & 63 & 23 \\
Cumulative (\%) & 73 & 86 & 63 & 86 \\
\hline
\end{tabular}




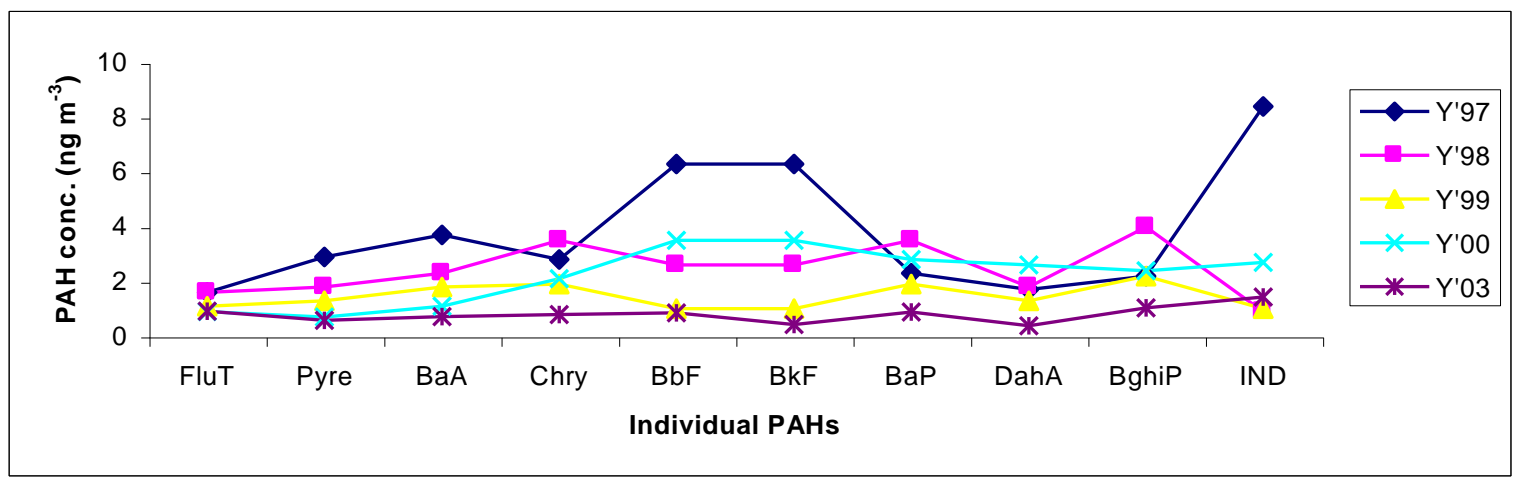

Fig 1: Comparison of PAHs concentrations in Delhi before and after the implementation of CNG.

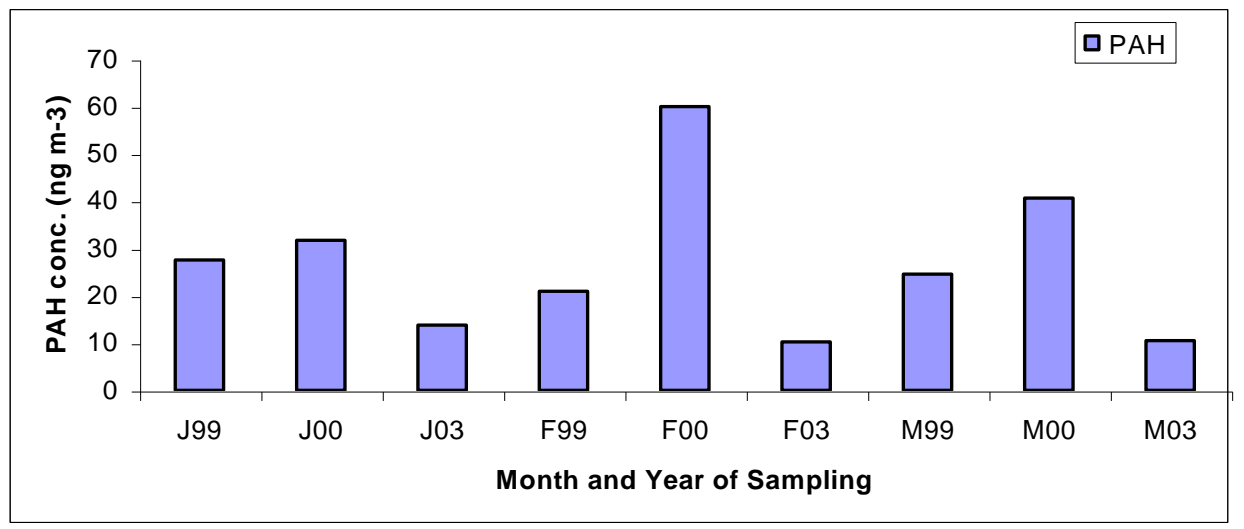

Fig 2: Comparisons of monthly (winter) total PAHs concentrations at BSZ traffic intersection. 

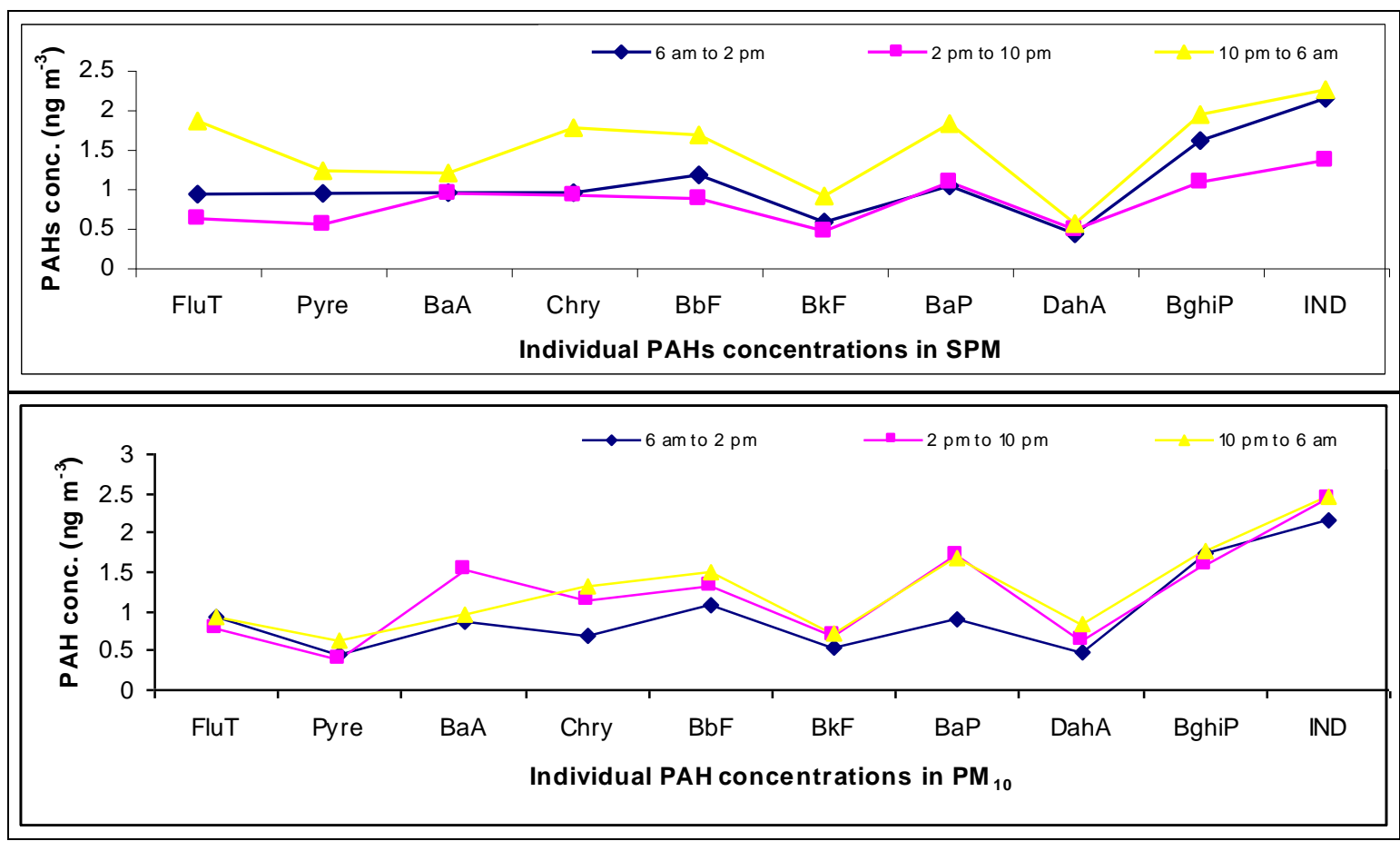

Fig 3: Daily variation of PAHs concentrations in SPM and $\mathrm{PM}_{10}$ at $\mathrm{BSZ}$ traffic intersection in Delhi during 2003.

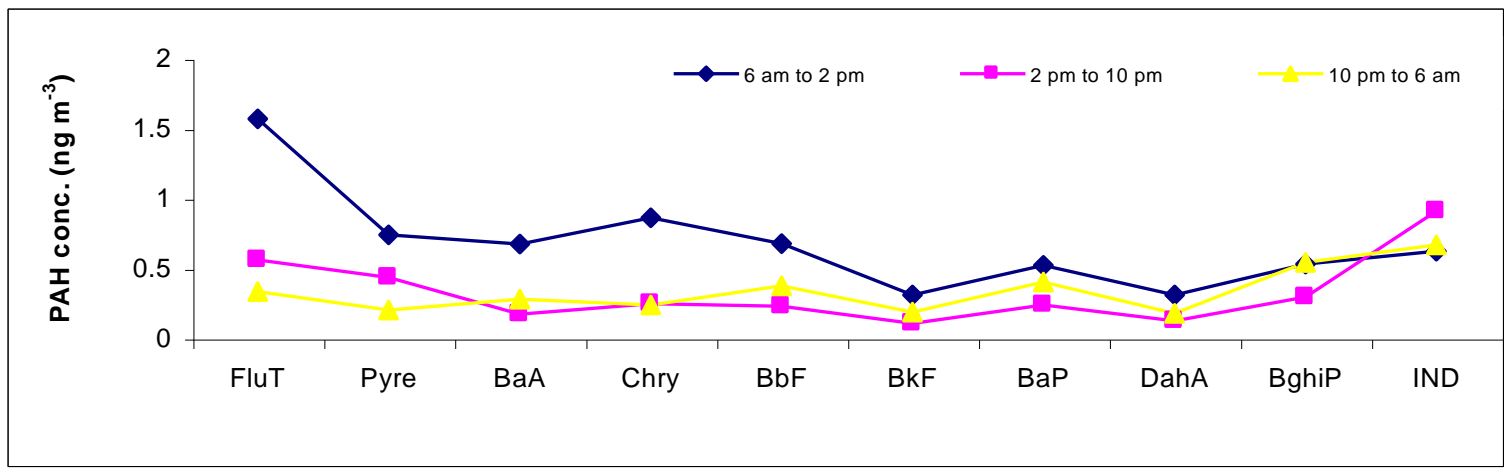

Fig 4: Daily variation of PAHs concentrations in SPM at the SF residential site in Delhi during 2003. 


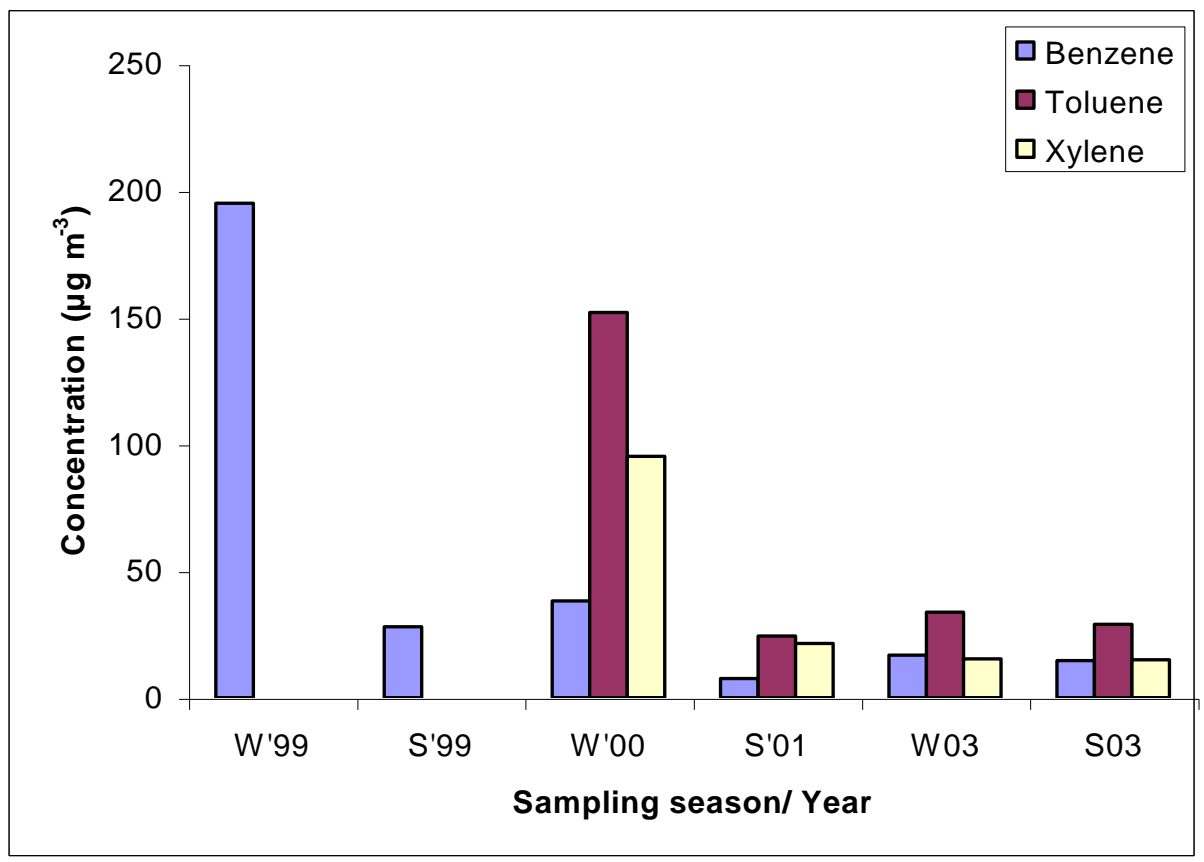

Fig 5: BTX concentration in Delhi at the BSZ traffic intersection.

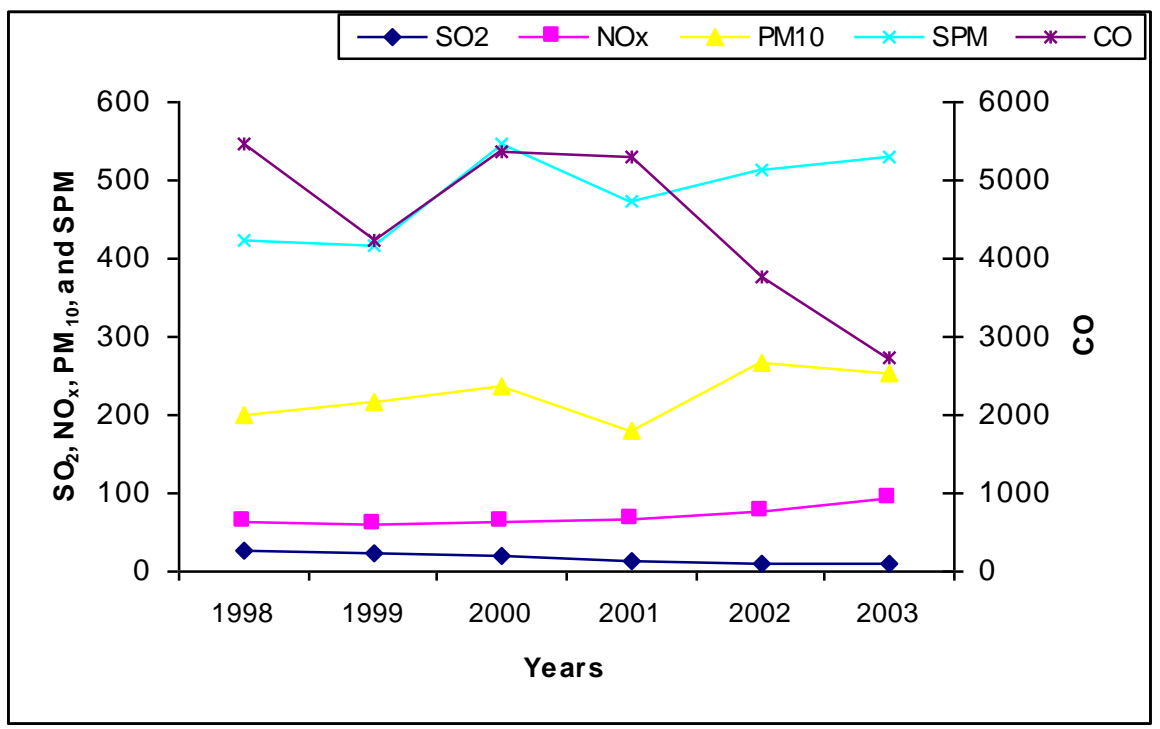

Fig 6: Variation in annual average concentration $\left(\mu \mathrm{g} \mathrm{m}^{-3}\right)$ of criteria pollutants. 